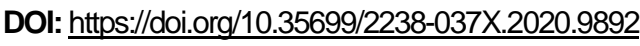

\title{
O USO DOS RECURSOS EM TECNOLOGIA ASSISTIVA PARA A PERMANÊNCIA DE SERVIDORES COM DEFICIÊNCIA NO AMBIENTE DE TRABALHO ${ }^{1}$
}

\author{
The use of resources in assistive technology for the permanence of servers \\ with disabilities in the work environment
}

\author{
SILVAJUNIOR, Geraldo Elias ${ }^{2}$ \\ FERRAZ, Denise Pereira de Alcantara ${ }^{3}$
}

\section{Resumo}

O presente estudo decorre de pesquisa de mestrado sobre como os recursos em tecnologia assistiva (TA), entendidos como ferramentas de apoio que também auxiliam às pessoas com deficiência (PCD) na realização das suas tarefas laborais, podem ser difundidos e melhor utilizados em uma Instituição Federal de Ensino Superior. Para tanto, teve como objetivo geral analisar como esses recursos possibilitam a permanência de servidores com deficiência no ambiente de trabalho da instituição selecionada para este estudo. A metodologia utilizada para alcançar os objetivos traçados tem caráter qualitativo. Os procedimentos de coleta de dados utilizados correspondem a entrevistas semiestruturadas com os servidores da instituição que se enquadram na categoria de PCD. Os dados coletados foram analisados por meio da Análise de Conteúdo, que pela inferência dedutiva irá verificar se uma política de inserção no mercado sem uma política de permanência é suficiente para garantir o acesso aos direitos das PCD e determinar como a tecnologia pode influenciar e melhorar essa política de permanência. Os resultados apontam que há um desconhecimento das PCD a respeito dos recursos de TA disponíveis, bem como uma inobservância institucional acerca de seus servidores com deficiência.

Palavras-chave: Tecnologia assistiva. Pessoa com deficiência. Trabalho.

\section{ABStract}

The present study stems from a master's research on how assistive technology (AT), understood as support tools that also assist people with disabilities (PWD) in the performance of their work tasks, can be disseminated and better used in a Federal Institution of Higher Education. Therefore, it had as general objective to analyze how these resources allow the permanence of disabled employees in the work environment of the institution selected for this study. The methodology used to achieve the objectives outlined is qualitative. The data collection procedures used correspond to semi-structured interviews with the institution's servers that fall under the PWD category. The data collected were analyzed through Content Analysis, which by deductive inference will verify that a policy of insertion in the market without a permanence policy is sufficient to guarantee access to the rights of the PWD and determine how technology can influence and improve this policy of permanence. The results indicate that there is an ignorance of the PWD regarding the available AT resources, as well as an institutional disregard for their disabled servers.

Keywords: Assistive technology. People with disabilities. Work.

\footnotetext{
${ }^{1}$ O presente artigo é resultante de pesquisa de mestrado e toma como base um recorte da dissertação intitulada “Tecnologia assistiva e as contribuições para a permanência da pessoa com deficiência no ambiente de trabalho de uma Instituição Federal de Ensino Superior". A pesquisa foi aprovada pelo Comitê de Ética em Pesquisa do Centro Universitário de Itajubá, na data de 11 de abril de 2018, CAAE n 72685717.5.0000.5094, parecer n 2.594.375. Não possui financiamento de órgãos e/ou agências de fomento.

${ }^{2}$ Aluno do curso de Pós-graduação em Desenvolvimento, Tecnologias e Sociedade da Universidade Federal de Itajubá (Itajubá, MG). Técnico em Assuntos Educacionais da Universidade Federal de Itajubá. E-mail: geraldo.junior@unifei.edu.br.

${ }^{3}$ Doutora em Psicologia Social pela Universidade do Estado do Rio de Janeiro. Professora adjunta e pesquisadora da Universidade Federal de Itajubá no Programa de Pós-graduação em Desenvolvimento, Tecnologias e Sociedade. E-mail: deferraz@unifei.edu.br.
} 


\section{INTRODUÇÃO}

O presente trabalho aborda o uso de recursos em tecnologia assistiva (TA), entendidos como ferramentas de apoio que também auxiliam as pessoas com deficiência (PCD) na realização das suas tarefas laborais, e como eles podem ser difundidos e mais bem utilizados em uma Instituição Federal de Ensino Superior (IFES). Preliminarmente, entende-se que a universidade, na maioria das vezes, participa das políticas públicas voltadas para as PCD apenas por meio de editais de concursos públicos que atendam a Lei de Cotas $^{4}$ sem, contudo, levar em consideração quais serão as dificuldades que essas pessoas contratadas enfrentarão ao assumirem os cargos devido a um ambiente de trabalho despreparado para atender às suas necessidades.

O que se verificou a partir de observações iniciais do pesquisador, que também é servidor, foi a falta de conhecimento a respeito dos recursos em TA por parte da gestão de pessoas da instituição e por parte dos próprios servidores com deficiência, conforme identificado também nos relatos que serão aqui apresentados, que resulta em uma menor disponibilização, utilização e adaptação do ambiente de trabalho desses servidores.

A realização desta pesquisa justifica-se pela promulgação da Lei Brasileira de Inclusão (LBI)5, que é a mais recente lei brasileira voltada para as PCD. Embora as legislações anteriores à LBI garantam os direitos já conquistados por este grupo, essa nova legislação objetiva reafirmar e promover em condições de igualdade o exercício dos direitos e das liberdades fundamentais pelas PCD.

Conforme mencionado, a LBI vem reafirmar o exercício pleno de cidadania e os direitos já adquiridos pelas PCD. No que concerne ao exercício de cargo público, a pessoa terá assegurado o uso de tecnologias apropriadas, quando necessário, para o exercício de suas atividades (BRASIL, 2015). Diante disso, os estudos a respeito dos recursos em TA se mostram importantes instrumentos para que a IFES se adapte à essa nova realidade e coloque em prática o cumprimento da lei.

O Art. 74 da LBI corrobora com as ideias de fomento ao desenvolvimento de pesquisas que visem a aprimorar, desenvolver e difundir os recursos em TA.

Art. 74 O poder público desenvolverá plano específico de medidas com a finalidade de criar mecanismos de fomento à pesquisa e à produção nacional de tecnologia assistiva, inclusive por meio de concessão de linhas de crédito subsidiado e de parcerias com institutos de pesquisa oficiais (BRASIL, 2015, p. 6).

Outro fator relevante, que serviu como embasamento para a referida pesquisa, trata do Termo de Ajuste de Conduta (TAC) firmado entre a IFES estudada e o Ministério Público Federal (MPF), em 15 de fevereiro de 2011. Nesse termo foi constatado que a IFES não estava adaptada em conformidade com o que dispõe o Decreto n. 5.296/2004, que regulamentou as Leis Nos. 10.048/2000, que dá prioridade de atendimento às PCD e a 10.098/2000, que estabelece normas gerais e critérios básicos para a promoção da

\footnotetext{
${ }^{4}$ Lei n.․ 8.213 (Lei de Cotas), de 24 de julho de 1991, dispõe sobre os planos de benefícios da previdência e sobre a contratação da PCD. De acordo com o Art. 93 da referenciada Lei, a empresa com 100 ou mais funcionários está obrigada a preencher de dois a cinco por cento dos seus cargos com beneficiários reabilitados ou pessoas com deficiência.

${ }^{5}$ Lei n.o 13.146, de 06 de julho de 2015, Lei Brasileira de Inclusão da Pessoa com Deficiência (Estatuto da Pessoa com Deficiência), destinada a assegurar e a promover, em condições de igualdade, o exercício dos direitos e das liberdades fundamentais pelas pessoas com deficiência, visando à sua inclusão social e cidadania.
} 
acessibilidade das PCD ou das pessoas com mobilidade reduzida, entre outras providências. Nesse TAC foram firmados compromissos a serem cumpridos durante um determinado período que iria de 2011 a 2015, no entanto, verificou-se que as ações se prorrogaram até o momento da realização deste estudo.

As ações firmadas nesse TAC são consoantes às ideias de Galvão Filho (2009), que dispõem sobre uma sociedade que seja adaptada às necessidades das PCD e não o oposto.

O indivíduo será mais ou menos limitado, em termos de funcionalidade e participação, quanto mais ou menos deficiente ou acessível for o seu ambiente. As intervenções e modificações devem ocorrer, dessa forma, também na sociedade, para que esta possa tornar-se realmente acessível e inclusiva (GALVÃO FILHO, 2009, p. 216).

Conforme apontado por Bampi, Guilhem e Alves (2010, p. 04), o modelo social da deficiência "é fruto das desvantagens ou restrições provocadas pela organização social contemporânea que pouco ou nada considera aqueles que possuem lesões físicas e os exclui das principais atividades da sociedade". Esse modelo estruturou-se em oposição ao modelo médico da deficiência, que reconhece na lesão, na doença ou na limitação física a causa primeira da desigualdade social e das desvantagens vivenciadas pelas PCD, ignorando o papel das estruturas sociais para a sua opressão e marginalização.

Desse modo, observa-se que nas sociedades atuais - em que todos os indivíduos compõem uma sociedade democrática, que visa o respeito aos seus mais sérios valores - a defesa dos indivíduos e seus direitos deve ser feita em sua plenitude e em decorrência dos princípios jurídicos da igualdade, da justiça social e do bem-estar. Assim, essa pesquisa se mostra relevante em vários aspectos, além de contribuir para que a instituição, como um órgão público, esteja de acordo com o cumprimento da lei.

No que diz respeito à complexidade do objeto de estudo e ao fato de que essa pesquisa possui um caráter interdisciplinar, nota-se que a visão de uma única especialidade não seria suficiente para responder aos questionamentos acerca desse tema. Sendo assim,

\footnotetext{
Entende-se por interdisciplinaridade a convergência de duas ou mais áreas do conhecimento, não pertencentes à mesma classe, que contribua para o avanço das fronteiras da ciência e tecnologia, transfira métodos de uma área para outra gerando novos conhecimentos ou disciplinas e faça surgir um novo profissional com um perfil distinto dos existentes, com formação básica sólida e integradora (CAPES, 2009, p. 6).
}

Nesse contexto interdisciplinar, este trabalho se caracteriza pelas interfaces que envolvem as visões da área tecnológica, da área humana e da área social. Do ponto de vista da área tecnológica, aqui representada pelos recursos em TA, entende-se que a discussão não deve apenas abordar as responsabilidades de se desenvolver tecnologias voltadas para a inclusão das PCD, mas também a criação e implementação de políticas públicas para fomento de pesquisas nessa área. Dessa forma, a primeira interface entre a tecnologia e a dimensão social se constitui. Quanto à área humana, o objeto de estudo diz respeito a relação das PCD com os recursos tecnológicos e sociais como forma de incentivo à sua permanência no ambiente de trabalho. Essa inclusão está diretamente ligada aos direitos humanos e à dignidade da pessoa, concretizando a interface entre o humano, o tecnológico e o social.

Conforme já exposto, não se pode ignorar o fato deque, no atual cenário, os problemas aparecem de forma mais complexa e exigem propostas de pesquisa cada vez mais 
interdisciplinares. Além disso, traçar objetivos claros que auxiliem a alcançar as respostas aos questionamentos iniciais dos trabalhos é fundamental. Nesse ensejo, o objetivo geral deste estudo é entender como os recursos em TA disponíveis atualmente possibilitam a permanência das PCD no ambiente de trabalho da IFES.

Em função disso, os próximos tópicos serão destinados à descrição da metodologia adotada; um breve histórico das relações entre as PCD e o mundo do trabalho; a apresentação da legislação existente e das políticas relacionadas ao assunto; também serão abordados os recursos em TA e como eles influenciam a vida das PCD; por fim, serão apresentadas as discussões sobre os relatos da pesquisa no recorte aqui apresentado, e as considerações finais.

\section{Percurso metodológico}

No que diz respeito à construção do caminho metodológico, adotou-se aqui o método qualitativo, que é aquele capaz de "[...] incorporar a questão do significado e da intencionalidade como inerentes aos atos, às relações, e às estruturas sociais, sendo essas últimas tomadas tanto no seu advento quanto na sua transformação, como construções humanas significativas (MINAYO, 2007, p. 38)".

Com relação aos participantes do estudo, estes foram definidos de forma a proporcionar uma amostragem real da situação dos servidores com deficiência que compõem o quadro de servidores da universidade, de acordo com os seguintes critérios: ter sido aprovado em concurso público concorrendo às vagas de cotas destinadas às PCD ou não; ser servidor ativo da IFES; possuir algum tipo de deficiência (auditiva, física, visual ou intelectual).

As entrevistas semiestruturadas foram utilizadas, nesta pesquisa, como instrumento (ou técnica) do método qualitativo para complementar a coleta de dados. As questões abordadas nessas entrevistas foram elaboradas de forma a proporcionar um melhor entendimento da situação dos participantes, no que diz respeito a quais são as suas deficiências, como elas influenciam suas atividades laborais, quais os recursos em TA elas utilizam, como utilizam, se seriam capazes de desempenhar suas tarefas diárias sem o auxílio dessas tecnologias, entre outros dados relevantes para o estudo.

Os dados coletados por meio das entrevistas foram transcritos integralmente e analisados utilizando o método da Análise de Conteúdo (AC) proposto por Bardin (2011), que compreende as seguintes etapas: parte prática (análises de entrevistas); os métodos de análise (categorização e inferência) e as técnicas de análise (análise categorial), que se complementam.

Assim, após a definição dos participantes, das técnicas de coleta e análise dos dados, a pesquisa de campo foi iniciada via contato prévio com o Departamento de Pessoal (DPE) e o Núcleo de Acessibilidade e Inclusão (NAI) da IFES, com o objetivo de ter acesso aos dados dos servidores que declaram ser PCD para uma futura abordagem e agendamento das entrevistas. Nesse primeiro momento, foi informado uma quantidade estimada de servidores na condição de PCD - sete indivíduos - e que, após a submissão da pesquisa ao comitê de ética e posterior aprovação, os dados de cada um deles seriam liberados aos pesquisadores.

Após a aprovação pelo comitê na data de 11 de abril de 2018, CAAE $n^{\circ}$ 72685717.5.0000.5094, parecer $n^{\circ} 2.594 .375$, os dados foram disponibilizados aos 
pesquisadores e iniciou-se a fase de contato e agendamento das entrevistas. A participação foi oficializada através do aceite do termo de consentimento livre e esclarecido. Os resultados serão apresentados no tópico destinado às discussões dos dados. Antes, porém, entender o histórico das relações entre as PCD e o mundo do trabalho, além da legislação pertinente ao tema, é fundamental para a posterior análise dos dados da pesquisa.

\section{Um bReVe histórico sobre as Pessoas com Deficiência e suas Relações COM O TRABALHO}

Ao iniciar as pesquisas sobre as relações das PCD e a permanência delas no ambiente de trabalho, verificou-se a necessidade de se realizar um levantamento histórico a respeito de como se constituiu esse processo e algumas questões surgiram nesse contexto. Como as relações de trabalho e as PCD eram vistas no passado e como são vistas na atualidade? Como se consolidou a legislação existente que garante o acesso das PCD ao mercado de trabalho? Essa consolidação se deu através de movimentos sociais e lutas por esses direitos? Dessa forma, o desenvolvimento deste tópico buscou auxiliar no esclarecimento de tais questionamentos.

Nesse sentido, algumas pesquisas identificadas sugerem a existência de que têm sido promovidas discussões e reflexões críticas a respeito da acessibilidade e inclusão das PCD no universo do trabalho (COUTINHO, RODRIGUES E PASSERINO, 2017; VILELA E LEITE, 2017; GUIMARÃES, MARTINS E BARKOKÉBAS, 2015). Contudo, apesar dos gradativos avanços que as $P C D$ vêm conquistando no Brasil em relação aos direitos e à legislação, a participação ativa dessas pessoas na sociedade, relacionada à plena inclusão na esfera do trabalho, ainda se encontra distante do esperado (LIMA E JURDI, 2014).

Historicamente, os primeiros relatos sobre a relação das PCD com o trabalho remetem à Grécia Antiga, e têm nesta seus principais fundamentos e possibilidades de compreensão de como esta interação acontecia (CARVALHO-FREITAS, 2007). Conforme apontado, também, por Galvão Filho (2009), no período clássico conhecido como o período de formas perfeitas na arquitetura e na arte -, o valor das pessoas estava em sua função social e na cisão entre trabalho intelectual e trabalho manual, ou seja, pode-se inferir que não havia lugar para as PCD.

[...] sabe-se que na China Antiga, na Grécia e em outras culturas o assassinato de crianças com deficiência era algo aceito pela sociedade. Essas pessoas que nasciam "deformadas" eram consideradas como subumanas, como seres anormais, malformados, por isso as suas famílias recebiam apoio do Estado e do grupo social onde estavam inseridas para matar ou abandonar as crianças com deficiência a própria sorte. Pensando, por exemplo, na cultura greco-romana e o seu ideal de homem atlético, guerreiro, pronto para a luta, podemos inferir com facilidade porque não havia lugar nesse tipo de mundo para uma pessoa com um defeito físico: a sua deficiência não lhe permitiria ser forte, viril, ser um bom soldado (GALVÃO FILHO, 2009, p. 87).

Durante o levantamento dos dados históricos a respeito das PCD e o trabalho, identificou-se que os períodos correspondentes a Idade Média, Idade Moderna e início da Revolução Industrial representaram poucos avanços em relação às oportunidades de trabalho oferecidas às PCD (CARVALHO-FREITAS, 2007; MARCONDES, 2002). No entanto, nos séculos que seguem a Revolução Industrial, especificamente no Séc. XX, "são criadas, no mundo inteiro, instituições especializadas no atendimento das 
deficiências e implantados programas de reabilitação" (CARVALHO-FREITAS, 2007, p.71). Além disso, as organizações intergovernamentais ${ }^{6}$ passaram a apoiar a equiparação de oportunidades para as PCD e a criar um intercâmbio de conhecimentos sobre a deficiência.

O período pós Segunda Guerra Mundial (1945-1973), por sua vez, marcou uma época em que o status das PCD começou a se modificar, visto que:

Nesse período, os países europeus estavam em uma situação precária e precisavam de homens para o mercado de trabalho (subsistência/sobrevivência); por outro lado, os excombatentes, apesar de mutilados pela guerra, detinham um capital social e cultural diferenciado; representavam os esforços de luta dos países e eram reconhecidos como pessoas capazes de contribuir com a sociedade, apesar de suas deficiências (CARVALHOFREITAS, 2007, p. 72).

Ainda de acordo com a autora, verifica-se, nesse momento histórico, que essas situações combinadas propiciaram o início das mudanças conceituais em relação às PCD, marcando o início de um processo de legalização do direito ao trabalho para esse grupo. Além disso, esses fatos obrigaram, principalmente a Europa Ocidental, a rever seus critérios de exclusão, com o objetivo de absorver a contribuição social necessária das PCD (CARVALHO-FREITAS, 2007).

A partir das décadas de 1960 e 1970, notadamente nos Estados Unidos, ocorreu uma forte defesa dos direitos humanos e civis pelos movimentos sociais de minorias. Esse movimento da sociedade, dos grupos minoritários e das próprias PCD, contribuiu para o surgimento de uma nova perspectiva ideológica em relação à questão, com forte ênfase nos direitos, na iniciativa individual e na autonomia dessas pessoas (CARVALHOFREITAS, 2007; GOSS, GOSS E ADAM-SMITH, 2000).

Com relação ao cenário brasileiro, até a década de 1980 o conceito de normalidade7 relacionado às PCD ainda predominava. No entanto, as ações dessa perspectiva começaram a se modificar visando à reabilitação dessas pessoas para sua integração nas atividades da sociedade. Abriu-se a perspectiva de integração social das PCD por meio da reabilitação e a sua adequação ao sistema social (OMOTE, 1994).

Assim, nos anos seguintes houve uma confluência de interesses: as PCD se organizaram e reivindicaram equiparação de oportunidades e garantia dos direitos civis; o Estado precisou diminuir suas despesas públicas, inclusive com o seguro social das PCD; e as organizações mundiais pressionaram pela defesa dos direitos humanos das minorias, fatos estes que acabaram por contribuir para o surgimento das leis em defesa dos direitos das PCD e o aumento de sua maior inserção no mercado de trabalho.

Ao refletir sobre essas questões, tendo como foco a análise do processo histórico da relação das sociedades e do mercado de trabalho com as PCD, pode-se observar que o estado permanente de segregação e de exclusão a que estas pessoas foram submetidas, tem determinado limites claros para o seu desenvolvimento e, praticamente, impossibilitado a construção de uma identidade positiva, de consciência crítica e do

\footnotetext{
${ }^{6}$ Alguns exemplos de organizações intergovemamentais que passaram a apoiar as equiparações de igualdade das PCD: ONU (Organização das Nações Unidas), OMS (Organização Mundial da Saúde), UNESCO (Organização das Nações Unidas para a Educação, a Ciência e a Cultura) e OIT (Organização Internacional do Trabalho).

${ }^{7}$ No passado, quando a desinformação e o preconceito a respeito das pessoas com deficiência eram maiores, a sociedade acreditava na normalidade das pessoas sem deficiência, ou seja, fundamentavam tais crenças nas ideias de que eram anormais as pessoas que tivessem algum tipo deficiência (Sassaki, 2003).
} 
exercício da cidadania. $\mathrm{Na}$ tentativa de superar esses obstáculos, foram pensados instrumentos legislativos a fim de garantir a plena participação das PCD em sociedade, aos quais nos referimos a seguir.

\section{Evolução normativa para as Pessoas com Deficiência}

Conforme mencionado, as consequências de conflitos armados, entre outros fatores, impulsionaram a promoção das leis que hoje asseguram os direitos das PCD. A ocorrência de duas guerras mundiais foi um importante marco para o estudo da proteção dessas pessoas, pois fizeram aumentar, significativamente, o número de pessoas com alguma deficiência física, como, por exemplo, os mutilados de guerra; o que pressionou o Estado a assumir sua posição de agente protetor (MOREIRA, 2011; ARAUJO, 1996). Nesse contexto, apesar da intensificação do debate mundial sobre a garantia de direito das PCD, até a década de 1980 pouco se concretizou a este respeito.

Somente em julho de 1990, muitos anos após o desenrolar das guerras mundiais e suas consequências, foi assinado o maior expoente legislativo acerca das PCD nos Estados Unidos, o ADA - Americans with Disabilities Act (MOREIRA, 2011). Porém, os movimentos sociais que buscavam equiparação de direitos pelas PCD começaram muito antes desta década, juntamente com a luta de outros movimentos sociais: "assim como os negros lutaram contra a segregação racial, as PCD lutaram e marcharam em favor da igualdade (MAYERSON, 1992, p. 22)".

Semelhante ao que aconteceu com os negros e as mulheres, o Congresso dos EUA percebeu que era necessária uma legislação para erradicar práticas discriminatórias também contra as PCD (MAYERSON, 1992). Assim, o ADA foi criado para trazer igualdade a um grupo até então sem representatividade. E, embora o ADA seja a mais importante lei para as PCD nos Estados Unidos, vale destacar que existem outras leis que asseguram os direitos a esse grupo de pessoas.

No contexto brasileiro, a legislação em prol das PCD também é muito recente. No entanto, o número elevado de PCD não tem a mesma causa dos países da Europa e dos Estados Unidos. Segundo Moreira (2011, p. 63), "o índice de pessoas com deficiência no Brasil se deve em grande parte aos acidentes de trânsito, acidentes de trabalho, à carência alimentar e à falta de higiene".

Além disto, o Brasil, diferentemente dos Estados Unidos, tem sua legislação baseada em várias constituições ao longo da história. Apenas em 1988, quando foi promulgada a atual Constituição - reconhecida como Constituição Cidadã e base para todos os decretos, portarias e resoluções oficiais às PCD -, é que surgiram diversas normas no intuito de regulamentar, facilitar e acelerar a integração social das PCD (RÊGO, 2004).

A mais recente lei brasileira referente às PCD é a $L B I$, que se destina a reforçar, assegurar e a promover em condições de igualdade o exercício dos direitos e das liberdades fundamentais pelas PCD, visando à sua inclusão social. De acordo com Gabrilli (2016), o texto da LBI tem como base a Convenção da ONU, de 2008, sobre os direitos das PCD, o primeiro tratado internacional de direitos humanos a ser incorporado pelo ordenamento jurídico brasileiro como emenda constitucional.

Além das medidas instituídas pela Convenção, tais como o acesso à saúde, educação, trabalho, cultura, lazer, informação, a LBI busca também atender a demandas específicas brasileiras, como exemplo a carência de serviços públicos (GABRILLI, 2016). 
É importante ressaltar que sua composição partiu do pressuposto de que não deve haver nenhum retrocesso dos direitos já conquistados. Não obstante, o texto foi pensado para não repetir mandamentos legais já previstos em outras normas, à exceção de disposições de decretos que foram elevadas ao status de lei.

Em suma, pode-se afirmar que a nova lei trouxe novidades, repetiu alguns conceitos e, por fim, trouxe vetores que devem conduzir a administração pública e privada na tarefa da inclusão. Dessa forma, pode-se afirmar também que a LBI não é um compilado de leis, mas um documento que altera algumas já existentes para harmonizá-las à Convenção Internacional.

No que tange à questão do trabalho, o Artigo $37 \mathrm{da} \mathrm{LBl}$ assegura a colocação competitiva das PCD "em igualdade de oportunidades com as demais pessoas, nos termos da legislação trabalhista e previdenciária na qual devem ser atendidas as regras de acessibilidade, o fornecimento de recursos de tecnologia assistiva e a adaptação razoável no ambiente de trabalho" (BRASIL, 2015, p. 5). É válido destacar que, mesmo antes da promulgação da LBI, a Lei n.ㅇ․․ 8.213 de 1991 - Lei de Cotas - já garantia a contratação obrigatória de PCD na proporção estabelecida em seu Artigo 93 (BRASIL, 1991).

\title{
INSERÇÃO E PERMANÊNCIA NO AMBIENTE DE TRABALHO: DEFINIÇÕES DOS RECURSOS EM TECNOLOGIA Assistiva
}

Apesar de ainda ocorrerem casos de segregação e discriminação relacionados às oportunidades de trabalho envolvendo as PCD, a inclusão desse grupo vem ganhando espaço na sociedade atual. Como citado anteriormente, leis específicas garantindo essa liberdade básica e outros direitos já existem, porém não basta apenas garantir que essas pessoas tenham um lugar no mercado de trabalho, mas garantir um ambiente favorável para a sua permanência e seu desenvolvimento profissional.

\begin{abstract}
A inclusão da PCD ao mercado de trabalho é um direito, independente do tipo de deficiência que apresente e de seu grau de comprometimento. No entanto, ainda presenciamos inúmeros casos de discriminação e exclusão, talvez, pela falta de conhecimento da sociedade de que esse cidadão tem direito à convivência não segregada e $\mathrm{o}$ acesso aos recursos disponíveis aos demais cidadãos (ARANHA, 2003, p. 5).
\end{abstract}

Atualmente, evidenciam-se, ainda, algumas dificuldades enfrentadas pelas PCD ao ingressarem no mercado de trabalho, dentre as quais se destacam: o uso inadequado dos recursos disponíveis para desenvolver programas de emprego; elaboração de avaliações através de critérios inadequados; e espaços físicos e logísticos do ambiente de trabalho organizados de maneira excludente (OLIVEIRA, GOULART JUNIOR E FERNANDES, 2009).

Apesar dessa realidade estar se modificando gradualmente, resta a crença de que suas especificidades são um impeditivo para o trabalho. Nesse viés, as manifestações e lutas para inclusão das PCD no mercado de trabalho ganham importantes aliados advindos dos avanços tecnológicos e dos recursos em TA, pois eles devem ser entendidos como uma ferramenta de auxílio que irá promover a ampliação de uma habilidade funcional deficitária ou possibilitará a realização da função desejada que se encontre impedida por circunstância da deficiência. 
Com relação aos recursos em TA, várias são as terminologias utilizadas, tais como: Tecnologia Assistiva (EUA), Tecnologia de Assistência (CIF/OMS), Tecnologia de Apoio (Comissão Européia/ EUSTAT) e Ajudas Técnicas (Ministério da Saúde). Dentre todas essas terminologias, nesse trabalho foi adotada a expressão Tecnologia Assistiva, por ser mais conhecida e utilizada no Brasil.

[...] encontramos com mais frequência, em nosso país, a expressão "Tecnologia Assistiva", principalmente no meio acadêmico, em cursos e disciplinas do ensino superior, tanto na graduação como na pós-graduação, e em documentos e iniciativas de órgãos públicos. Por exemplo, o Ministério da Ciência e Tecnologia (MCT) realizou, em 2005, uma chamada pública de projetos de pesquisa e desenvolvimento em 'Tecnologia Assistiva', a serem apoiados financeiramente através de sua Financiadora de Estudos e Projetos (FINEP) (GARCIA E GALVÃO FILHO, 2012, p. 20).

No Brasil esses termos são empregados, na maioria das vezes, como sinônimos. Apesar disso, a questão da necessidade de uma padronização da terminologia adotada no país foi trabalhada pelo Comitê de Ajudas Técnicas $(\mathrm{CAT})^{8}$. Quanto ao conceito estipulado para o termo TA, o supracitado Comitê elaborou e aprovou por unanimidade, em dezembro de 2007, a adoção da seguinte formulação:

É uma área do conhecimento, de característica interdisciplinar, que engloba produtos, recursos, metodologias, estratégias, práticas e serviços que objetivam promover a funcionalidade, relacionada à atividade e participação de pessoas com deficiência, incapacidades ou mobilidade reduzida, visando sua autonomia, independência, qualidade de vida e inclusão social (CAT, 2007, p. 3).

Nesse sentido, Bersch e Tonolli (2006, p. 9) identificam os recursos em TA como "todo o arsenal de recursos e serviços que contribuem para proporcionar ou ampliar habilidades funcionais de pessoas com deficiência e consequentemente promover vida independente e inclusão". Em complemento, segundo Sonza et al (2013, p.199), "o propósito da tecnologia assistiva reside em ampliar a comunicação, a mobilidade, o controle do ambiente, as possibilidades de aprendizado, trabalho e integração na vida familiar, com os amigos e na sociedade em geral". Portanto, muito além de servirem para compensar as especificidades das PCD, os recursos em TA podem garantir o acesso e a permanência no trabalho em igualdade de condições.

Também a LBI, no seu Art. 37, traz as seguintes colocações acerca dos recursos em TA e das PCD na inclusão no mercado de trabalho:

Art. 37, parágrafo único. A colocação competitiva da pessoa com deficiência pode ocorrer por meio de trabalho com apoio, observadas as seguintes diretrizes: [...] II - provisão de suportes individualizados que atendam a necessidades específicas da pessoa com deficiência, inclusive a disponibilização de recursos de tecnologia assistiva, de agente facilitador e de apoio no ambiente de trabalho (BRASIL, 2015, p. 5).

Importante ressaltar que, mesmo com todos os benefícios e melhorias que os recursos em TA podem prover, o uso dessas tecnologias no Brasil ainda é restrito e alguns dos principais motivos são: "falta de conhecimento do público em geral, falta de orientação aos usuários pelos profissionais da área de reabilitação, alto custo de algumas delas,

\footnotetext{
${ }^{8}$ O Comitê de Ajudas Técnicas é um comitê permanente criado no âmbito da Secretaria Especial dos Direitos Humanos da Presidência da República (SEDH/PR), ligado à Coordenadoria Nacional para a Integração da Pessoa Portadora de Deficiência (CORDE), um órgão dessa Secretaria. Esse Comitê foi instituído pela Portaria 142, de 16 de novembro de 2006, e teve a sua criação prevista e determinada pelo Decreto $n^{\circ}$. 5.296/2004, em seu Artigo 66.
} 
carência de produtos no mercado e falta de financiamento para pesquisa" (SONZA et al, 2013, p. 200). Nas falas dos participantes entrevistados, foram destacados importantes fatores que corroboraram com tais afirmações, conforme análises a seguir.

\section{REALIDAdES E DIFICULdAdES do AMBIENTE LABORAL DOS SERVIDORES Com DEFICIÊNCIA}

As análises dos dados iniciaram do processo de transcrição e codificação das entrevistas realizadas durante a pesquisa. Os dados apresentados a seguir são um recorte do trabalho e através deste, foi possível identificar quatro categoriais principais ou eixos principais; cada categoria situou-se no contexto dos trechos selecionados das falas de P1 e P2, e contaram com o respaldo do referencial teórico. Desse modo, as nomeações dadas as categorias e subcategorias podem ser observadas conforme Tabela 1.

Tabela 1- Categorias principais e subcategorias

\begin{tabular}{|c|c|}
\hline Categorias Principais & Subcategorias \\
\hline \multirow{6}{*}{ Caracterização dos participantes } & Gênero \\
\hline & Tipo de deficiência \\
\hline & Instrução formal \\
\hline & Local onde trabalha \\
\hline & Cargo que ocupa \\
\hline & Aprovação em vagas destinadas as PCD \\
\hline \multirow{7}{*}{ Percepções sobre as experiências de trabalho } & Experiências anteriores \\
\hline & Experiências no trabalho atual \\
\hline & Adaptações do ambiente laboral \\
\hline & Ambiente de trabalho público e privado \\
\hline & Relacionamento com os colegas \\
\hline & Dificuldades para desempenhar as funções \\
\hline & Desvios de função \\
\hline \multirow{5}{*}{ Percepções sobre os recursos em TA } & Conhecimento \\
\hline & Utilização \\
\hline & Disponibilização dos recursos pela IFES \\
\hline & Desempenho das funções sem os recursos \\
\hline & Divulgação \\
\hline \multirow{3}{*}{ Expectativas dos sujeitos } & Atenção aos servidores PCD \\
\hline & Adaptação universal \\
\hline & Conscientização \\
\hline
\end{tabular}

Fonte: dados da pesquisa

As categorias principais serviram como pontos norteadores durante as análises. Com relação a primeira categoria principal, ou seja, sobre a categorização dos participantes, tem-se que do total dos sete servidores com deficiência que compõem o quadro efetivo da IFES estudada, dois participantes (P1 e P2) foram selecionados para as entrevistas iniciais, sendo duas mulheres. As idades de P1 e P2 variavam entre 30 a 40 anos e o tipo de deficiência predominante entre elas era a deficiência visual, e o nível de escolaridade de ambas era o superior completo.

Tabela 2- Perfil demográfico dos sujeitos da pesquisa

\begin{tabular}{cccccc}
\hline Participantes $(\mathrm{P})$ & Gênero & Idade & Formação & Deficiência & Cotas \\
\hline P1 & Feminino & 34 & Graduação & Visual & Não \\
\hline P2 & Feminino & 36 & Graduação & Visual & Sim \\
\hline
\end{tabular}

Fonte: dados da pesquisa 
Inicialmente buscou-se compreender qual o conhecimento as entrevistadas apresentavam sobre os recursos em TA, isto é, quais os recursos elas utilizavam, como utilizavam, se estes recursos eram disponibilizados pela IFES, entre outras informações relevantes, a fim de estabelecer os eixos temáticos principais. Percebeu-se que ambas possuíam algum conhecimento sobre os recursos em TA, mesmo que de forma superficial, no entanto, verificou-se que P2 detinha maior conhecimento em relação à P1, talvez pelo fato de ser membro do Núcleo de Acessibilidade e Inclusão (NAl) e ter maior contato com as questões relacionadas a este tema.

A exemplo, destaca-se a fala da entrevistada P1 onde foi mencionado ter ouvido falar o que são os recursos em TA e afirmado não fazer utilização de tais recursos em seu ambiente de trabalho, conforme trecho a seguir: "Sim, eu já ouvi falar, mas nunca usei nenhum" (P1, 2017). Porém, nota-se que o seu conhecimento era superficial, visto que ela fazia utilização das ferramentas do Windows, como, por exemplo, a lupa de aumento de texto, e este recurso pode ser considerado como uma TA. Tal situação é exemplificada por Bersch (2017):

Num sentido amplo percebemos que a evolução tecnológica caminha na direção de tornar a vida mais fácil. Sem nos apercebermos utilizamos constantemente ferramentas que foram especialmente desenvolvidas para favorecer e simplificar as atividades do cotidiano, como os talheres, canetas, computadores, controle remoto, automóveis, telefones celulares, relógio, enfim, uma interminável lista de recursos, que já estão assimilados à nossa rotina e, num senso geral, são instrumentos que facilitam nosso desempenho em funções pretendidas (BERSCH, 2017, p. 2).

Nesse sentido, pode-se inferir que a utilização de alguns recursos em TA, especialmente os mais simples, acaba sendo tão corriqueira na vida das PCD que sua utilização não é perceptível, o que gera inconsistências quando estas pessoas são questionadas se fazem utilização desses recursos.

Outro ponto interessante que deve ser destacado, ainda referente à primeira categoria, diz respeito à desvalorização do ingresso no serviço público através das cotas disponibilizadas as PCD. A fala destacada de P1 exemplifica tal situação:

Não, tudo que eu sei até agora eu corri atrás, até porque eu entrei por vagas normais, acho que seu eu tivesse entrado por uma vaga de deficiente talvez me fosse oferecido alguma coisa. '[...] eu concorri a uma vaga normal e passei pelo meu mérito', então eu acho que meio que cabe a mim enfrentar isso, sabe (P1, 2017).

No Brasil, desde 1990, a Lei n. 8.112/1990 define reserva máxima de $20 \%$ das vagas em concursos públicos para as PCD (BRASIL, 1990). Já o Decreto № 3.298/1999, em seu Art. 37, estabelece que o percentual mínimo de 5\% das vagas, em concursos públicos, seja destinado às PCD (BRASIL, 1999). Nesse contexto, segundo Neves e Lima (2010), tem-se que:

Um dos eixos mais inovadores das políticas públicas brasileiras dos últimos anos tem sido a adoção de políticas afirmativas voltadas para a diminuição de diferenças socioeconômicas entre algumas categorias sociais. Essas políticas estão pautadas na ideia de que, para garantir a igualdade de direitos, é necessária a ação do Estado no sentido de oferecer condições especiais aqueles que, por razões de ordem social, econômica, cultural ou política, estão originalmente em situação desfavorável de competição com outros membros da sociedade (NEVES; LIMA, 2010, p. 57). 
É notório que essas ações afirmativas objetivam proporcionar igualdades reais às minorias, entendidas aqui como os grupos desfavorecidos economicamente, as mulheres, os idosos, os negros e as PCD. No entanto, tais ações não devem nos levar a acreditar que os méritos dos esforços empregados por esse grupo de pessoas, em conseguir essas vagas, são menores que os esforços daqueles que concorrem as vagas de ampla concorrência.

Em complemento à ideia desses esforços e no que se refere ao nível de instrução formal dos participantes, observou-se que ambas as entrevistadas detinham formação superior completa e isso vai ao encontro das ideias de Morais (2017), onde a educação tem papel fundamental no rompimento da exclusão social das PCD. E é através da educação que elas obtêm mais oportunidades para a vida social e profissional, desconstruindo a visão de pessoa vulnerável e incapaz, dando lugar a autonomia e independência, buscando, através da educação profissional, a qualificação, a capacitação e o reconhecimento no mercado de trabalho (MORAIS, 2017).

No que concerne às análises da segunda categoria, percepções sobre as experiências de trabalho, foi possível inferir que o cenário laboral ao qual as PCD estão sujeitas atualmente sofreu uma mudança drástica se comparado aos dados históricos apresentados inicialmente. Além disso, a deficiência não é mais um impeditivo para a contratação dessas pessoas.

Sim, é ... eu tive experiências anteriores de trabalho, eu trabalhei numa escola de música, num escritório de contabilidade e como recepcionista do convento aqui de ltajubá (P1, 2017).

No mesmo contexto, nas falas de P2 pôde-se observar que embora houvessem experiências de trabalho anteriores e que ela possuísse educação superior completa, as atividades atribuídas a ela ainda eram limitadas devido à deficiência.

Eu estive trabalhando numa cidade próxima aqui de Itabira, trabalhei cinco anos lá como auxiliar administrativa [...]. Lá como era a câmara municipal que eu trabalhava, eu, particularmente, não tinha muita função, ficava no telefone e na recepção (P2, 2017).

Identifica-se, assim, a necessidade de assegurar às PCD as mesmas condições necessárias para permanecerem e crescerem na instituição, da mesma maneira que são oferecidas aos outros servidores. Segundo Gil (2002, p. 11), "fica cada vez mais clara a importância estratégica de criar uma realidade social inclusiva, que absorva as demandas e necessidades de todos os segmentos sociais".

Percebe-se que não é suficiente a existência de medidas legislativas que busquem apenas assegurar a acessibilidade e a igualdade de senviços sociais, enquanto a realidade encontrada nos indica um cenário no qual os profissionais com deficiência estão submetidos a desvantagens e preconceitos que imperam na sociedade e no ambiente laboral (MAIA, CAMINO E CAMINO, 2011).

Ainda no que concerne às experiências de trabalho, a garantia de estabilidade do servidor público foi um fator que trouxe maior conforto no ambiente laboral para as PCD, visto que a competição é menor que a encontrada no ambiente privado. As falas de P1 a seguir corroboraram com essas ideias, veja:

Se eu trabalhasse numa indústria ou uma grande multinacional ou alguma coisa assim, eu acredito que até pela competição que existe entre funcionários e eu entrando por uma vaga normal que não seja uma vaga de deficiente, talvez eu sofresse alguma coisa que fosse me tirar um pouco o espaço de trabalho. Tipo assim, a concorrência, as pessoas mais 
adaptadas e as pessoas que não têm deficiência renderiam melhor do que eu, e aí eu ficaria em desvantagem e as vezes até fosse mandada embora do trabalho né. Mas como eu trabalho, aliás funcionária pública, eu to garantida aqui, to tranquila (P1, 2017).

Segundo Marques et al. (2016, p. 54), em seus estudos sobre mudança organizacional e satisfação no trabalho público, "a maioria dos servidores está muito satisfeita, principalmente, com a estabilidade no emprego, seguida pela integração social, supervisão, relevância social do trabalho e condições de trabalho". Apesar da carreira no serviço público não oferecer alguns benefícios que o setor privado oferece, como por exemplo, o FGTS9, a estabilidade é um fator compensatório relevante.

Com relação às questões de adaptação do ambiente de trabalho, foram verificadas as necessidades de pequenos ajustes que se tornaram diferenciais para a execução das atividades diárias. No entanto, conforme mencionado anteriormente, a falta de conhecimento a respeito dos recursos em TA, que poderiam ser importantes auxiliares nessas adaptações, acaba prejudicando os servidores.

Evidencia-se que a falta de conhecimento a respeito dos recursos em TA é um fator importante nas adaptações do ambiente de trabalho do servidor com deficiência, no entanto, a responsabilidade pelo processo de disseminação e ampliação deste conhecimento deve ser dividido entre a instituição e o próprio servidor. Nas falas de P2 pôde-se observar que o envolvimento do sujeito com deficiência na busca pelos recursos e posterior aquisição pela universidade deve ocorrer em conjunto.

É assim ... a pessoa tem que falar né o que ela precisa, também procurar os recursos que ela acha que vai atender e que vai ajudar a minimizar as dificuldades dela. E ela falar e a universidade adquirir. Não tem outra forma (risos) (P2, 2017).

Conforme já mencionado, os conhecimentos a respeito dos recursos em TA por P2 eram maiores do que os conhecimentos de P1. Esse fato explica o motivo das adaptações do ambiente de trabalho de uma serem maiores do que de outra. Conforme apontado nas falas durante as entrevistas, apesar de ambas possuírem algum tipo de deficiência visual, P2 tinha à disposição mais recursos em TA para minimizar essas dificuldades.

Ah por conta dos equipamentos que a IFES adquiriu e tudo [...], mas ler até que nem tanto porque agora eu tenho a lupa e ela me auxilia muito. Tenho o scanner também, que a IFES adquiriu, aí facilita muito o meu trabalho (P2, 2017).

O fato de uma participante ter mais recursos em TA disponíveis do que a outra ressaltou outro ponto para ser destacado. Pelas falas das entrevistadas, percebeu-se o tratamento diferenciado que a IFES fornece aos servidores com deficiência que foram aprovados através das vagas de cotas destinadas às PCD e aqueles que entraram por meio das vagas de ampla concorrência. Cabe ainda destacar que no controle da diretoria de pessoal da IFES os servidores que não entraram pelas vagas de cotas ou que possuíam uma deficiência adquirida não constavam nos registros como PCD.

Dessa forma, o que se verificou é que o modelo de tratamento conferido aos servidores nesse molde acaba os prejudicando de alguma maneira, seja no fornecimento dos

\footnotetext{
${ }^{9}$ O Fundo de Garantia do Tempo de Serviço (FGTS) foi criado com o objetivo de proteger o trabalhador demitido sem justa causa, mediante a abertura de uma conta vinculada ao contrato de trabalho. No início de cada mês, os empregadores depositam em contas abertas na Caixa, em nome dos empregados, o valor correspondente a $8 \%$ do salário de cada funcionário. O FGTS é constituído pelo total desses depósitos mensais e os valores pertencem aos empregados que, em algumas situações, podem dispor do total depositado em seus nomes. Maiores informações podem ser verificadas em: http:/hww.fgts.gov.br/Pages/sou-trabalhador/o-que.aspx.
} 
recursos em TA necessários ao desenvolvimento de suas tarefas ou no reconhecimento das suas limitações, podendo ocasionar prejuízos até mesmo nas suas avaliações de desempenho.

Segundo Simonelli et al. (2013), verifica-se que outras barreiras que circundam o mundo das PCD e dificultam sua inclusão no ambiente laboral, vão além das informações desatualizadas a respeito de suas incapacidades e das dificuldades encontradas nas estruturas arquitetônicas fora dos parâmetros de acessibilidade, ou seja, alcançando também o tratamento diferenciado pelo órgão empregador.

\section{CONSIDERAÇÕES}

A elaboração deste estudo foi motivada pelo fato de que diversos recursos em TA estão disponíveis atualmente, com objetivo de auxiliar às PCD na realização tanto das tarefas diárias como nas tarefas laborais, entretanto, isso não ocorre de forma integral, ou seja, esses recursos não são utilizados e a permanência dos servidores com deficiência no ambiente de trabalho acaba sendo prejudicada.

O que se pôde notar com os avanços da pesquisa é que existem diversos recursos em TA disponíveis para as mais variadas atividades, no entanto, falta divulgação a respeito deles e da própria legislação vigente que garante sua disponibilização. Notou-se, também, que as pressões dos grupos interessados conduziram à criação de estratégias de apoio às PCD e que há uma gama de leis que visam a resguardá-las no Brasil. Apesar de todas as conquistas, ainda há muito o que se fazer para avançar. Ademais, ainda é ineficiente a aplicação das leis na forma de políticas públicas, garantindo acesso aos recursos em TA e sua disseminação, para que as PCD possam participar de maneira concreta e digna no desenvolvimento social e econômico do país.

Em suma, esses dados indicam a necessidade de uma sensibilização a fim de se quebrar resistências no ambiente de trabalho, especialmente as relacionadas à ideia de que essas pessoas não possuem escolarização ou capacidade para buscarem aperfeiçoamento contínuo. Por fim, espera-se que essas análises colaborem com a equipe de gestão de pessoas, fornecendo subsídios que viabilizem a permanência de PCD no ambiente de laboral, com igualdade de condições e com exercício pleno de sua cidadania.

\section{REFERÊNCIAS}

ARANHA, Maria S. F. Trabalho e emprego: instrumento de construção de identidade pessoal e social. São Paulo: SORRI-BRASIL. Brasília: Corde, 2003, 40 p.

ARAUJO, Luiz A. D. A proteção constitucional das pessoas portadoras de deficiência. 2 ed. Brasília: Corde, 1996. $122 \mathrm{p}$.

BAMPI, Luciana N. S; GUILHEM, Dirce; ALVES, Elioenai D. Modelo social: uma nova abordagem para o tema deficiência. In: Rev. Latino-Am. Enfermagem, vol.18, n.4, jul-ago 2010, 9 telas.

BARDIN, Laurence. Análise de conteúdo. São Paulo: edição 70, 2011, 229 p.

$\mathrm{BERSCH}$, Rita. Introdução à tecnologia assistiva. Porto Alegre: RS. 2017. Disponível em: http://www.assistiva.com.br/Introducao_Tecnologia_Assistiva.pdf. Acesso em: 10 jun. 2017.

BERSCH, Rita; TONOLLI, José. Introdução ao conceito de tecnologia assistiva. Disponível em: http://www.assitiva.com.br. Acesso em: 10 out. 2016. 
BRASIL. Lei №. 8.112, de 11 de dezembro de 1990. Dispõe sobre o regime jurídico dos servidores públicos civis da União, das autarquias e das fundações públicas federais. Diário Oficial da República Federativa do Brasil, Poder Executivo, Brasília, DF, 19 abr. 1991. Seção I, p. 01.

BRASIL. Lei №. 8.213, de 24 de julho de 1991. Dispõe sobre os Planos de Benefícios da Previdência Social e dá outras providências. Diário Oficial da República Federativa do Brasil, Poder Executivo, Brasília, DF, 25 jul. 1991. Seção I, p. 14809.

BRASIL. Decreto №. 3.298, de 20 de dezembro de 1999. Regulamenta a Lei $N^{\circ} 7.853$, de 24 de outubro de 1989, dispõe sobre a Política Nacional para a Integração da Pessoa Portadora de Deficiência, consolida as normas de proteção, e dá outras providências. Diário Oficial da República Federativa do Brasil, Poder Executivo, Brasília, DF, 21 dez. 1999. Seção I, p. 10.

BRASIL. Lei №. 13.146, de 06 de julho de 2015. Institui a Lei Brasileira de Inclusão da Pessoa com Deficiência (Estatuto da Pessoa com Deficiência). Diário Oficial da República Federativa do Brasil, Poder Executivo, Brasília, DF, 07 jul. 2015. Seção I, p. 2-72.

CAPES. Documento de área da avaliação trienal de 2009. Disponível em: http://www.capes.gov.br/images/stories/download/avaliacao/INTER03ago10.pdf. Acesso em: 10 mai. 2017.

CARVALHO-FREITAS, Maria N. A inserção de pessoas com deficiência em empresas brasileiras: um estudo sobre as relações entre concepções de deficiência, condições de trabalho e qualidade de vida no trabalho. 2007. 309 f. Tese (Doutorado em Administração) - Universidade Federal de Minas Gerais, Belo Horizonte, 2007.

CAT, 2007. Ata da Reunião VII, de dezembro de 2007, Comitê de Ajudas Técnicas, Secretaria Especial dos Direitos Humanos da Presidência da República (CORDE/SEDH/PR). Disponível em: http://www.mj.gov.br/corde/arquivos/doc/Ata_VII_Reunião_do_Comite_de_Ajudas_Técnicas.doc. Acesso em: 20 jun. 2017.

COUTINHO, Katia. S.; RODRIGUES, Graciela F.; PASSERINO, Liliana M. O trabalho de colaboradores com deficiência nas empresas: com a voz os gestores de recursos humanos. In: Rev. Bras. Educ. Espec., vol.23, n.02, Marília, 2017.

GABRILLI, Mara. LBI - Lei Brasileira de Inclusão. Guia digital sobre a LBI. 2016. Disponível em: http:/maragabrilli.com.br/wp-content/uploads/2016/03/Guia-sobre-a-LBI-digital.pdf. Acesso em: 10 mai. 2017.

GALVÃO FILHO, Teófilo A. A Tecnologia Assistiva: de que se trata? In: MACHADO, G. J. C.; SOBRAL, M. N. (Org.). Conexões: educação, comunicação, inclusão e interculturalidade. 1 ed. Porto Alegre: Redes Editora, p. 207-235, 2009.

GARCÍA, Jesus C. D.; GALVÃO FILHO, Teófilo. A. Pesquisa Nacional de Tecnologia Assistiva. São Paulo: ITS BRASILIMCTI-SECIS, 2012. 68 p.

GIL, Marta. (Coord.). O que as empresas podem fazer pela inclusão das pessoas com deficiência. São Paulo: Instituto Ethos, 2002.

GOSS, David; GOSS, Fiona; ADAM-SMITH, Derek. Disability and employment: a comparative critique of UK legislation. The International Journal of Human Resource Management, v. 11, n. 4, p. 807-821, Aug. 2000.

GUIMARÃES, Bruno; MARTINS, Laura B.; BARKOKÉBAS, Béda J. Workplace accommodation to people with disabilities: a case study in civil construction. In: Fisioterapia em Movimento, vol.28, n.04, Curitiba, 2015.

LIMA, Laís B.; JURDI, Andrea P. S. Empregabilidade de pessoas com deficiência no município de Santos/SP: mapeamento de políticas públicas e práticas institucionais. In: Revista Brasileira de Educação Especial, v. 20, n. 4, Marília, 2014.

MAIA, Luciana. M.; CAMINO, Cleonice; CAMINO, Leoncio. Pessoas com deficiência no mercado de trabalho: uma análise do preconceito a partir das concessões de profissionais de recursos humanos. São João del-Rei: Pesquisas e práticas psicossociais, v. 6, n. 1, p. 78-91, 2011.

MARCONDES, Danilo. Iniciação à história da filosofia: dos pré-socráticos a Wittgenstein. 7. ed. Rio de Janeiro: J. Zahar, 2002. 
MARQUES, Antônio L.; BORGES, Renata; REIS, Isabella C. Mudança organizacional e satisfação no trabalho: um estudo com servidores públicos do estado de Minas Gerais. In: Rev. Adm. Pública, Rios de Janeiro, RJ, v. 50, n. 01, 2016, p. 51-58.

MAYERSON, Arlene. The history of the ADA: a movement perspective. In: GOSTIN, L. O.; BEYER, H. A. (Ed.). Implementing the Americans with disabilities act: rights and responsabilities of all Americans. Baltimore: P. H. Brookes, 1992. p. 17-27.

MINAYO, Maria C. S. O desafio do Conhecimento - Pesquisa Qualitativa em Saúde. Rio de Janeiro: Hubitec-Abrasco, 2007.

MORAIS, Karine $\mathrm{H}$. $\mathrm{O}$ mercado de trabalho e a pessoa com deficiência intelectual: entraves e oportunidades. In: Revista Espacios, vol.38, n.12, 2017, p.26.

MOREIRA, Lilian B. Socialização organizacional e dinâmica identitária de pessoas com deficiência: um estudo no Brasil e nos Estados Unidos. 2011. 158 f. Dissertação (Mestrado em Administração) Universidade Federal de Lavras, Lavras, 2011.

NEVES, Paulo S. C; LIMA, Marcus E. O. Percepções da justiça social e atitudes de estudantes prévestibulandos e universitários sobre as cotas para negros e pardos nas universidades públicas. In: Ações afirmativas e políticas inclusivas no ensino público superior: a experiência da Universidade Federal de Sergipe. São Cristóvão: Editora UFS, 2010, p. 182.

OLIVEIRA, Marileide A.; GOULART JUNIOR, Edward; FERNANDES, José M. Pessoas com deficiência no mercado de trabalho: considerações sobre políticas públicas nos Estados Unidos, União Europeia e Brasil. Revista Brasileira de Educação Especial. Associação Brasileira de Pesquisadores em Educação Especial - ABPEE, v. 15, n. 2, p. 219-232, 2009.

OMOTE, Sadao. Perspectivas para a conceituação de deficiências. In: Revista Brasileira de Educação Especial. Araraquara, p. 127-135, 1994.

P1. Entrevista I. [set. 2017]. Entrevistador: Geraldo Elias Silva Junior. Itajubá, 2017. 1 arquivo .mp3 (17 min). A Entrevista na íntegra encontra-se transcrita no Apêndice $C$ da dissertação de mestrado.

P2. Entrevista II. [out. 2017]. Entrevistador: Geraldo Elias Silva Junior. Itajubá, 2017. 1 arquivo .mp3 (15 min). A Entrevista na íntegra encontra-se transcrita no Apêndice $D$ da dissertação de mestrado.

RÊGO, Márcia C. dos S. O portador de deficiência e o novo Código Civil. Jus Navigandi, Teresinha, v. 8, n. 224, fev. 2004.

SASSAKI, Romeu K. Inclusão: Construindo uma sociedade para todos. 5. Ed. Rio de Janeiro: WVA, 2003.

SIMONELLI, Angela P. et al. Inclusão de pessoas com deficiência no trabalho - relato de experiência. Cad. Ter. Ocup. UFSCar, v. 21, n. 1, p. 119-130, 2013.

SONZA, Andréa $P$. et al. Acessibilidade e tecnologia assistiva: pensando a inclusão sociodigital de PNEs. Bento Gonçalves: Ministério da Educação, 2013, 367 p.

VILELA, Laiza O.; LEITE, Lúcia P. Effects of an intervention on the participation of people with disability in the workplace. In: Rev. Estudos de Psicologia, v. 34, n. 01, Campinas, 2017.

Data da submissão: 03/01/2019

Data da aprovação: 30/06/2020 